\title{
Isotachophoresis-based sample preparation of cellulases in sugarcane juice using bovine serum albumin as a model protein
}

\author{
Ruchi Gupta $^{\mathrm{a}, *}$, Sara J. Baldock ${ }^{\mathrm{b}, 1}$, Peter R. Fielden ${ }^{\mathrm{b}, 2}$, Jeff E. Prest ${ }^{\mathrm{b}, 1}$, Bruce D. Grieve ${ }^{\mathrm{a}, 3}$ \\ a School of Electrical and Electronics Engineering, The University of Manchester, PO Box 88, Sackville Street Building, Sackville Street, Manchester, M60 1QD, UK \\ ${ }^{\mathrm{b}}$ School of Chemical Engineering and Analytical Science, Manchester Interdisciplinary Biocentre, The University of Manchester, Oxford Road, Manchester, M13 9PL, UK
}

\section{A R T I C L E I N F O}

\section{Article history:}

Available online 24 August 2010

\section{Keywords:}

Bio-ethanol

Sugarcane

Cellulases

Bovine serum albumin (BSA)

Sample preparation

Isotachophoresis

\begin{abstract}
A B S T R A C T
The foremost requirement of quantification of cellulases expressed in genetically modified sugarcane is an efficient sample clean-up. This work investigates the feasibility of isotachophoresis for this purpose. An electrolyte system comprising a leading electrolyte of $10 \mathrm{mM}$ formic acid at $\mathrm{pH} 9.0$ and a terminating electrolyte of $10 \mathrm{mM} \beta$-alanine was devised and used to perform isotachophoresis of cellulases. The use of a simple front cutting method removed a majority of interfering species in the juice, thereby resulting in the formation of a distinct zone of desired proteins. In comparison to techniques such as ultrafiltration and liming, the analysis time and loss of desired proteins was lower when the sample was prepared by using isotachophoresis. Hence, isotachophoresis was an ideal choice for purification of the proteins in question from the remaining components in the juice.
\end{abstract}

(C) 2010 Elsevier B.V. All rights reserved.

\section{Introduction}

The high cost of cellulosic enzymes present a major obstacle in realizing the potential economic and environment benefits of second-generation bio-ethanol, i.e. the conversion of waste biomass such as bagasse into ethanol. The integration of gene sequences expressing cellobiohydrolases $(\mathrm{CBH})$ and endoglucanase (EG) from Trichoderma longibrachiatum and $\beta$-glucosidase (BG) from Aspergillus niger into the sugarcane genome can provide lower cost cellulosic enzymes for ethanol production from bagasse [1]. But the concentration of expressed enzymes is likely to be dependent upon cane variety and cultivation conditions. Therefore, it is necessary to measure the concentration of these enzymes in every batch of harvested sugarcane for bio-ethanol process quality control.

Previously, enzyme activity assays have been used to quantify $\mathrm{BG}, \mathrm{CBH}$ and $\mathrm{EG}$ by measuring their activity on a number of natural substrates (e.g. carboxymethyl cellulose, filter paper) and synthetic substrates (e.g. p-nitrophenyl- $\beta$-D-cellobioside, p-nitrophenyl- $\beta$ D-glucopyranoside, p-nitrophenyl- $\beta$-D-lactoside) [2,3]. But the

\footnotetext{
* Corresponding author. Tel.: +44 161306 4889; fax: +44 1613064789.

E-mail addresses: ruchi.gupta@postgrad.manchester.ac.uk (R. Gupta), sara.baldock@manchester.ac.uk (S.J. Baldock), peter.fielden@manchester.ac.uk (P.R. Fielden), j.prest@manchester.ac.uk (J.E. Prest), bruce.grieve@manchester.ac.uk (B.D. Grieve).

1 Tel.: +44161306 8900; fax: +441613065201.

2 Tel.: +44161306 64889; fax: +441613065201

3 Tel.: +44161306 2815; fax: +441613064789.
}

non-specificity of enzymatic assays makes them unsuitable for quantifying the concentration of individual enzymes in a mixture. In addition, a majority of these assays measure the production of reducing sugars (e.g. glucose) [2], thereby requiring the removal of reducing sugars in the juice for an accurate estimation of the concentration of the enzymes. Monoclonal antibodies have been developed for highly specific enzyme-linked immunosorbent assays (ELISA) [4]. But the requirement to produce antibodies for each protein adds to the expense. In addition, the method involves a number of washing and incubation steps due to which it is laborious. Furthermore, the hot and humid environment in sugarcane mills may denature the antibodies and hence hamper the specificity of their interactions with the target proteins. Therefore, ELISA is unsuitable for on-site analysis of cellulases in sugarcane juice. Hence, techniques such as capillary zone electrophoresis (CZE) have been investigated recently for the separation and quantification of cellulases in a single step [5-9]. However, major challenge in using CZE for biological samples is that constituents such as salts and organic or inorganic acids, which are present in large quantities, reduce the separation efficiency of the technique, while other components such as undesirable proteins result in unpredictable shifts in migration time by binding to the capillary wall $[10,11]$. Furthermore, the short optical path length and small sample volumes involved in CZE often requires the use of suitable pre-concentration techniques to enhance its detection limits. Therefore, sample preparation, including clean-up and pre-concentration, plays a key role in the widespread application of CZE to real samples [11]. Similarly, CZE-based separation and quantification of cellulases in 
sugarcane juice requires an efficient sample clean-up and preconcentration.

Although purification of cellulolytic enzymes from culture filtrates of fungi has been studied previously, their isolation from sugarcane juice has not been reported. In general, the purification of these enzymes from the culture medium involves either their precipitation via organic solvents followed by their re-suspension in an appropriate buffer $[12,13]$ or filtration $[6,7]$ or ion-exchange chromatography [14-17]. It should however be noted, that unlike the culture medium which mainly consists of salts and surfactants [18], the juice consists of a large number of organic components such as organic acids, undesirable proteins, colouring pigments and sugars [19]. These interfering organic species may result in membrane fouling or blockages on using filtration. Similarly, they may precipitate or elute with the enzymes on using organic solvents or ion-exchange chromatography respectively. In other words, the methods used previously for the isolation of enzymes from the culture medium are not ideal for their separation from the juice.

Traditional techniques such as solid-phase extraction [20], liquid-liquid extraction [21,22], supported liquid membranes [23] and liming [24] have been studied for the removal of aconitic, lactic and carboxylic acids, phosphate, starch and dextran. But these techniques are not suitable for sample preparation of cellulases in sugarcane juice due to a number of reasons. While liming involves harsh treatment conditions (e.g. high temperature) which may denature proteins, other methods like liquid-liquid extraction may result in the removal of the desired enzymes due to their precipitation in the presence of organic solvents. In addition, online interfacing of these techniques with CZE is problematic due to buffer incompatibilities and differences in sample volumes as well as pumping mechanisms. These off-line sample preparation techniques also result in sample loss and possible contamination. The automatic transfer (i.e. on-line coupling) of the prepared sample also provides other advantages like reduction in analysis time and sample volume. Filtration is another technique that is gaining in popularity as a tool for clarification of sugarcane juice. In order to increase the on-line integration amenability of membranes with CZE, attempts have been made to replace the centrifugal force with electrical force to drive the movement of substances across membranes. However, the use of electrofiltration presents several challenges such as diminished efficiency due to the limiting current effect, plus undesirable electrochemical reactions that result in $\mathrm{pH}$ changes and bubble formation. Although the use of a membrane has its merits, such as physical separation of the desired components without the addition of any extraneous chemicals and a lower energy consumption than other clarifying methods [25,26], membrane fouling and blockages continue to be a serious design and operational concern in juice purification [27].

The ability to tailor electrolyte systems to remove unwanted sample components makes isotachophoresis (ITP) a versatile sample preparation technique. The potential for eliminating expensive, unreliable high-pressure pumps and replacing them with compact, solid-state, high-voltage power supplies is another important factor in the favour of ITP. Hence, ITP is commonly coupled to CZE to combine the high sample loading and clean-up capacity of ITP with the high separation efficiency of CZE to achieve an accurate, high resolution and increased sensitivity quantification [28-31]. Therefore, this work develops an electrolyte system for isotachophoretic migration of BG, CBH and EG. This paper also presents the first use of ITP for purification of BSA from sugarcane juice which could then be analyzed by another separation process such as CZE. This is followed by a comparison of the effectiveness of ITP and other traditional techniques such as ultrafiltration and liming for the purpose.

\section{Experimental}

\subsection{Chemicals}

The electrolytes used in this work were prepared by using formic acid (98.4\%), Mowiol (40-88), tris(hydroxymethyl)aminomethane (Tris) (99.9\%), $\beta$-alanine (all: Aldrich, Gillingham, UK) and barium hydroxide $(0.05 \mathrm{M}$ volumetric standard, Riedel-de-Haën, Gillingham, UK). The calcium oxide used for liming was bought from Janssen, Buckinghamshire, UK. All solutions were prepared by using 18.2 M $\Omega$ water (Elga Maxima Ultra Pure, Vivendi Water Systems, High Wycombe, UK).

In order to make standard enzyme solutions, $\mathrm{CBH}$ and EG from T. longibrachiatum, BG from A. niger (Megazyme, Bray, Ireland) and bovine serum albumin (BSA; Aldrich, Gillingham, UK) were used. While BSA was provided in lyophilized form, the remaining proteins were supplied as suspensions in $3.2 \mathrm{M}$ ammonium sulphate solution. The initial concentration of BG, CBH and EG enzyme suspensions as supplied were $1.78 \mathrm{mg} / \mathrm{ml}, 10 \mathrm{mg} / \mathrm{ml}$ and $17.12 \mathrm{mg} / \mathrm{ml}$ respectively. Hence, $\mathrm{CBH}$, EG and BG were desalted using $10 \mathrm{kDa}$ molecular weight cut-off (MWCO) Vivaspin ${ }^{\mathrm{TM}} 6$ polyethersulfone (PES) columns (Sartorius, Surrey, UK) according to the manufacturer's instructions.

Frozen samples of fresh, raw sugarcane juice were provided by the Queensland University of Technology, Australia. Thus juice was defrosted in a water bath at $40^{\circ} \mathrm{C}$ to provide sample aliquots of $\sim 1.5 \mathrm{ml}$, which were stored subsequently at $-10^{\circ} \mathrm{C}$. Before analysis each defrosted aliquot was centrifuged at $14,000 \times g$ for $3 \mathrm{~min}$ (to remove solid particles such as sand) after which the supernatant was collected to perform sample preparation.

\subsection{Instrumentation}

An ItaChromII EA 202M (JH Analytik, Aalen, Germany) fitted with a fluorinated ethylene-propylene (FEP) co-polymer preseparation column of $0.8 \mathrm{~mm}$ internal diameter and total length of either $9 \mathrm{~cm}$ or $16 \mathrm{~cm}$ was used for ITP separations performed in this work. The pre-separation column was coupled to a $14 \mathrm{~cm}$ long, $0.3 \mathrm{~mm}$ internal diameter quartz analytical column via a bifurcation block. The bifurcation block, in addition to a $0.3 \mathrm{~mm}$ internal diameter capillary coupling the two columns, is equipped with a capillary that connects to the counter-electrode reservoir, thereby allowing single or dual column operation. Both pre-separation and analytical columns were fitted with on-column contactless conductivity detectors. In addition, the analytical column was equipped with a ultraviolet (UV) absorbance detector which was also used in this work. The ItaChromII EA 202M was controlled by using ITPWin Version 2.18 Control (KasComp, Bratislava, Slovakia). The software was also used to collect data at 50 samples/s and to calculate the relative step height ( $\mathrm{RSH}$ ) of sample components.

The columns were prepared by flushing with $\sim 10 \mathrm{ml}$ of $\mathrm{H}_{2} \mathrm{O}$ followed by $\sim 10 \mathrm{ml}$ of leading electrolyte (LE). The columns were washed with $\sim 1 \mathrm{ml}$ of LE between runs. A valve injection system comprising a $30 \mu \mathrm{l}$ sample loop was used to introduce samples into the separation system. The initial migration behavior of $\mathrm{BG}, \mathrm{CBH}$, EG and BSA using the chosen electrolyte system was studied by following a three-step program. Firstly, a driving current of $200 \mu \mathrm{A}$ was applied for $300 \mathrm{~s}$ in the pre-separation column. Following this, a current of $100 \mu \mathrm{A}$ was applied for $275 \mathrm{~s}$ during which conductivity data from the pre-separation column was recorded. Finally, a driving current of $25 \mu \mathrm{A}$ was used in the analytical column. During this time the conductivity and UV absorbance (at $280 \mathrm{~nm}$ ) traces were collected. The raw juice containing BSA (i.e. no sample clean-up) as well as the samples prepared by ultrafiltration and liming were also analyzed by following this method. 


\subsection{Sample preparation}

Sugarcane juice containing $10 \mathrm{mg} / \mathrm{ml}$ BSA was prepared via ITP using a four-step program. In step one a current of $200 \mu \mathrm{A}$ was applied for $300 \mathrm{~s}$ following which a current of $100 \mu \mathrm{A}$ was applied and a comparison value was set. In the third step, a current of $100 \mu \mathrm{A}$ was applied for $200 \mathrm{~s}$ and the data from the conductivity detector fitted to the pre-separation column were collected. Finally, a current of $25 \mu \mathrm{A}$ was applied for $15,000 \mathrm{~s}$, during which data from the analytical column were recorded.

In order to purify samples using ultrafiltration, $0.1 \mathrm{ml}$ of juice containing $10 \mathrm{mg} / \mathrm{ml} \mathrm{BSA}$ was added to a $10 \mathrm{kDa}$ MWCO membrane column (Vivaspin ${ }^{\mathrm{TM}} 500$, Sartorius). The volume of the sample in the column was reduced to $\sim 50 \mu$ l by centrifuging it at $14,000 \times \mathrm{g}$ for $20 \mathrm{~min}$. $50 \mu \mathrm{l}$ of water was added to the column, following which it was centrifuged $(14,000 \times g$ for $20 \mathrm{~min})$ to reduce the volume to $\sim 20 \mu \mathrm{l}$. Finally, the sample was collected by using a pipette after adding $\sim 80 \mu \mathrm{l}$ of water to the column. The collected sample $(\sim 100 \mu \mathrm{l})$ was mixed with $\sim 100 \mu \mathrm{l}$ of water and was analyzed by ITP.

The liming was performed by adding calcium oxide to the sample to increase its $\mathrm{pH}$ to 9.5 . Following this the sample was then heated at $60^{\circ} \mathrm{C}$ for $40 \mathrm{~min}$ until flocculation occurred. The resulting solution was centrifuged at $10,000 \times g$ for $10 \mathrm{~min}$. Finally, the supernatant was collected.

\section{Results and discussion}

\subsection{Design of electrolyte system}

The aim of this study was to use ITP as a sample preparation technique, the foremost demand on the electrolyte system was that the enzymes should migrate between the leading (LE) and the terminating electrolyte (TE). But previously there have been no studies reported into the migration behavior of $\mathrm{BG}, \mathrm{CBH}$ and $\mathrm{EG}$ under ITP conditions. Therefore, it was necessary to develop a new electrolyte system.

Since the average dissociation constant $\left(\mathrm{pK}_{\mathrm{avg}}\right)$ of crude biological mixtures is close to $\mathrm{pH} 7$ [32], ITP analysis of proteins in anionic form is usually carried out at high pH (greater than 8) [33] to make them sufficiently mobile, i.e. higher than the allowable minimum velocity of the TE anion [34]. In addition, a faster and more conductive TE could be chosen if the substances in question show reasonable effective mobilities. This in turn implies that higher separation currents can be employed and the analysis time can be reduced. However, LE systems with $\mathrm{pH}$ values of 10 and higher were not studied to avoid the unsafe region, i.e. $\mathrm{pH} \geq 10$, and hence to ensure that the ITP migration of the enzymes is not disturbed by $\mathrm{OH}^{-}$[34]. Furthermore, preliminary experiments with the LE of pH 9.5 demonstrated that the enzymes could not be bracketed between the tried LE and TE. Hence a pH of 9 was chosen for the LE.

However, despite choosing such a high $\mathrm{pH}$, it was still necessary to use a very low conductivity TE (i.e. $\beta$-alanine) to enable the isotachophoretic migration of EG (the slowest enzyme) through the separation channel. The disturbances introduced by carbonate contamination in the TE due to dissolution of atmospheric carbon dioxide in alkaline solutions was suppressed by the addition of barium hydroxide [33]. In order to reduce the potential drop across the system, the $\mathrm{pH}$ of the TE was increased to 9.6 via addition of barium hydroxide.

A high concentration of LE is desirable to increase the conductivity of electrolyte, thereby limiting Joule heat generation in the system. This in turn reduces the probability of bubble formation. Hence the reproducibility of work was not compromised. It should
Table 1

Composition of electrolyte system developed to allow the isotachophoretic migration of cellulases.

\begin{tabular}{lll}
\hline Electrolyte & Leading (LE) & Terminating (TE) \\
\hline Ion & Formate & $\beta$-Alanine \\
Concentration $(\mathrm{mM})$ & $10 \mathrm{mM}$ & $10 \mathrm{mM}$ \\
Counter ion & Tris & \\
$\mathrm{pH}$ & 9.0 & 9.6 \\
Additive & Mowiol $(0.05 \% \mathrm{wt} / \mathrm{v})$ & $\mathrm{Ba}(\mathrm{OH})_{2}(\sim 1 \mathrm{mM}$ to obtain \\
& & $\mathrm{pH}$ of 9.6$)$ \\
\hline
\end{tabular}

be noted that the chosen electrolyte concentration is in accordance with that used by Thormann et al. [35].

The findings of a previous study determined that the mobility of oxalate, malonate and citrate ions (i.e. species which are present in the juice) have higher mobilities than fomate [36]. A cautious approach of using formic acid was taken in order to ensure that a zone was observed for BG (which is the fastest moving enzyme in the mixture). The LE was buffered with Tris due to its superior buffering capacity at the chosen $\mathrm{pH}\left[32,37\right.$ ] due to its $\mathrm{p} K_{\mathrm{a}}$ of 8.1 [38]. Finally, 0.05\% (wt/v) Mowiol was added to suppress electroosmotic flow. A complete composition of the electrolyte system used in this work is provided in Table 1.

The conductivity traces of cellulases along with BSA are shown in Fig. 1. The injected amount of BG, BSA, CBH and EG were $51 \mu \mathrm{g}$, $75 \mu \mathrm{g}, 99 \mu \mathrm{g}$ and $96 \mu \mathrm{g}$ respectively. Although preliminary work was performed using lower concentrations of proteins (results not shown), the used concentrations gave visible step lengths that could be analyzed by using ITPWin software. It should be noted that the UV absorbance $(280 \mathrm{~nm})$ traces are not shown because they do not provide any additional information. From Fig. 1, it can be seen that BG, BSA, CBH and EG were bracketed between the LE and TE. It should be noted that due to the higher limit of detection of the conductivity detector (in comparison to the UV detector) and the smaller amount of BG injected into the system compared to the other three enzymes, the step corresponding to BG in Fig. 1(a) was not so prominent. However, it was observable in the UV trace (results not shown).

The RSHs of BG, BSA, CBH and EG were found to be $0.34,0.36$, 0.39 and 0.61 respectively. The analysis time $(\sim 60 \mathrm{~min})$ for each cellulosic enzyme was greater than the time required for analysing BSA. The increase in time required to detect the leading edge of cellulosic enzymes in comparison to BSA is due to the presence of an additional species, marked as ' $A$ ' in Fig. 1, in these enzymes. Since the enzymes were supplied as suspensions in $3.2 \mathrm{M}$ ammonium sulphate solution and contains sodium azide (as biocide), it is likely that some species present in enzyme standards results in a dip (marked as ' $A$ '). This is consistent with the observation that ' $A$ ' was absent in the blank and BSA. To summarize, the developed electrolyte system was found to be suitable for isotachophoretic migration of $\mathrm{BG}, \mathrm{CBH}$ and $\mathrm{EG}$.

\subsection{Sample preparation using ITP}

An ITP-based sample preparation method for purification of cellulases in sugarcane juice was developed by using a model sample solution consisting of BSA $(10 \mathrm{mg} / \mathrm{ml})$ in the raw juice. This is because the molecular weight of BSA is similar to some of the cellulosic enzymes. Furthermore, BSA is a low cost and widely available protein. Hence, for these reasons BSA was chosen as a model protein to develop the ITP-based sample purification method. Finally, as shown in Fig. 1, the mobility of BSA is similar to that of BG and $\mathrm{CBH}$ at the chosen $\mathrm{pH}$. Hence the choice of BSA as a model protein for cellulosic enzymes was considered to be reasonable.

The initial ITP analysis of the model sample solution showed that BSA could not be separated from the components in the sugarcane 

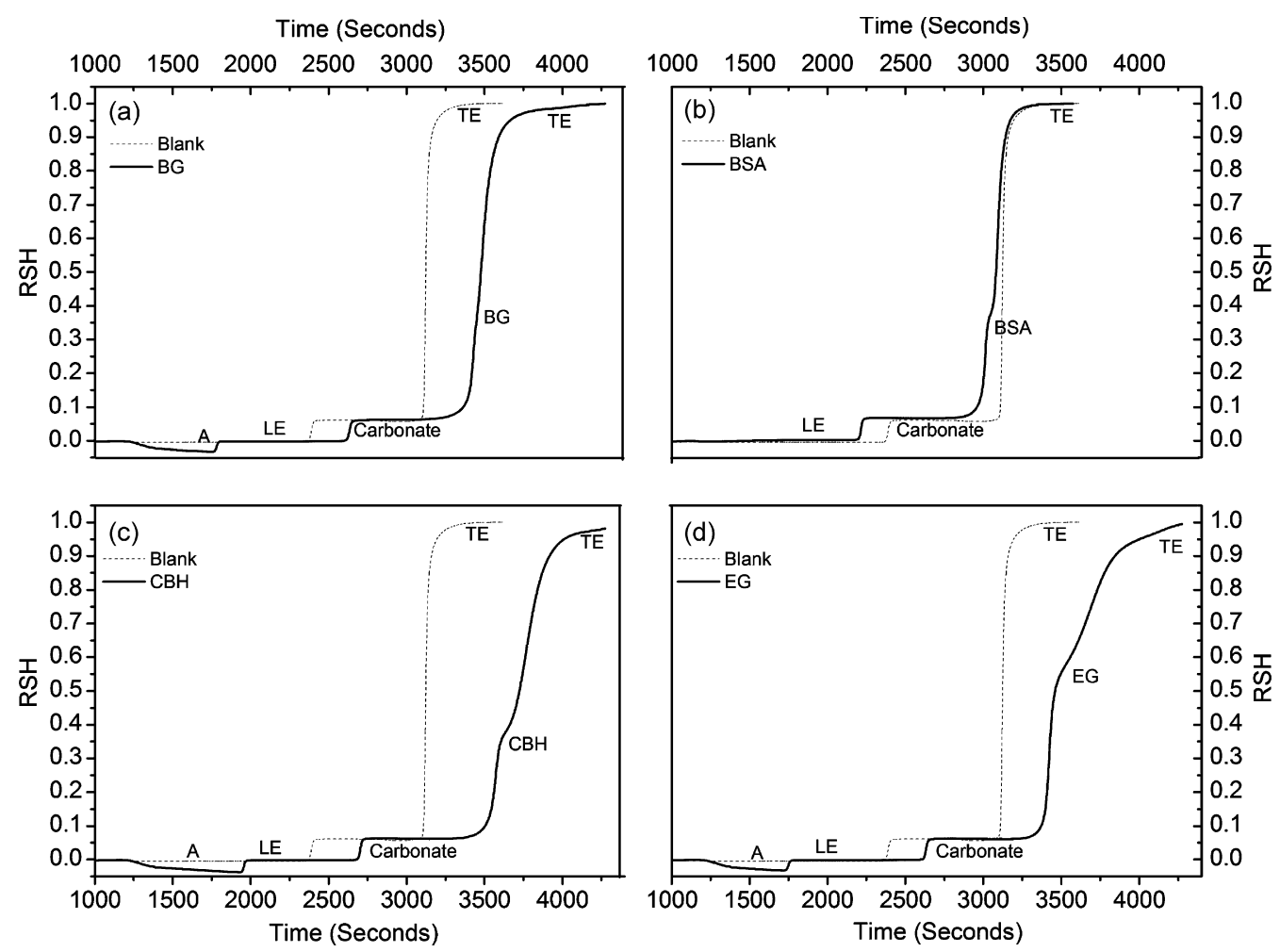

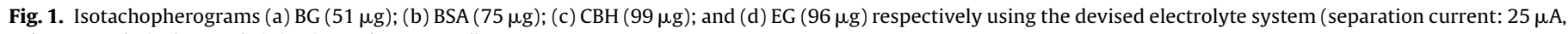
column: analytical; sample injection volume: $30 \mu \mathrm{l})$.

juice due to analytical column overloading (results not shown). The likely interfering species in the juice are salts and organic acids which have low $\mathrm{p} K_{\mathrm{a}}$ values. Therefore, in the alkaline $\mathrm{pH}$ range where cellulases are sufficiently mobile, these components will always be negatively charged and will migrate in the separation channel. In other words, modest changes in the $\mathrm{pH}$ of the LE will not eliminate or reduce these interfering components from the sample matrix. Therefore, it was necessary to discard the undesirable components of the sample via a front- or heart-cutting method to avoid overloading of the analytical column. In other words, the switching from the pre-separation to the analytical column should be initiated at the correct time to ensure that the entire sample of interest is transferred to the analytical column while the interfering components are discarded.

In order to develop such a method, the conductivity traces (obtained via the detector fitted to the pre-separation column) of the sugarcane juice with and without BSA were studied. But no notable differences were observed in the two isotachopherograms due to which it was impossible to predict the zone/region corresponding to BSA in the conductivity trace obtained (results not shown). Ideally, it is possible to predict this by using the information on the RSH of BSA solution in water. But in reality, the RSH of BSA in sugarcane juice and in water may be different due to unpredictable sample matrix effects. Hence, it was thought prudent to analyze the diluted (by a factor of 10) juice with and without BSA in order to estimate the BSA zone/region in the isotachopherogram.

From Fig. 2, it is clear that the signal for BSA lies in the region of $B$ to $B^{\prime}$. Although BSA formed a mixed zone with carbonate, a good separation between interfering species in the juice and $\mathrm{BB}^{\prime}$ was accomplished. This implies that the components preceding the sample could be discarded in order to clean the sample matrix without losing BSA. In order to ensure a complete transfer of BSA, while eliminating the components preceding the sample, the front end of the sample (marked as ' $\mathrm{B}$ ' in Fig. 3) should be allowed to travel to the bifurcation point before it is transferred to the analytical column.
To do so, the instrument was programmed such that the sample transfer to the analytical column occurred $200 \mathrm{~s}$ after the potential measured by the pre-separation column increased by $500 \mathrm{mV}$ (indicates that the front end of the sample has reached the detector) from its initial value.

As shown in Fig. 3, the removal of a majority of the unwanted species in the juice resulted in the formation of a distinct BSA zone. The ITP sample purification method was repeated 3 times and the step length and RSH of BSA were found to be $730 \pm 23 \mathrm{~s}$ and $0.27 \pm 0.02$ respectively. Following this, a series of dilutions of the sugarcane juice were prepared and the ITP front-cutting method was used successfully to obtain the BSA zone without any matrix interference. However, the use of the developed method for cleaning up of the juice diluted by a factor of 2 , required a longer

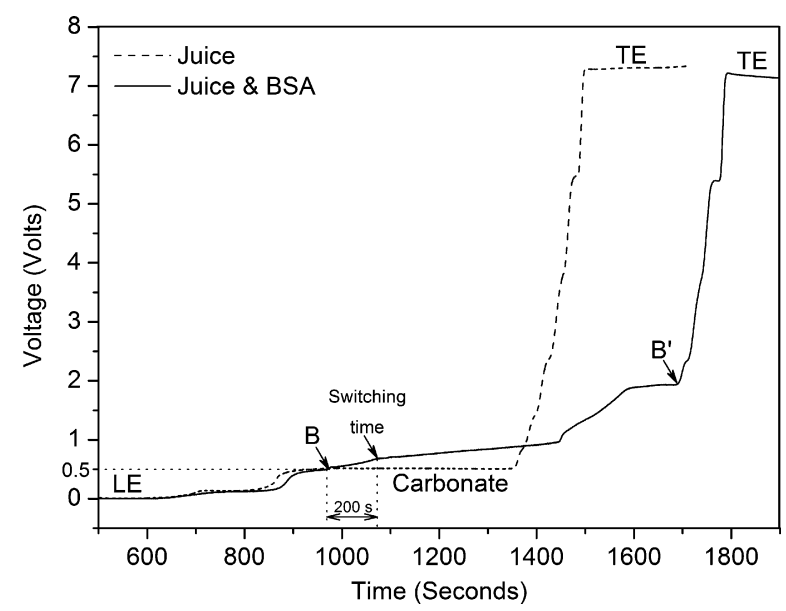

Fig. 2. A comparison of isotachopherograms of 10 times diluted juice with and without BSA (column: $9 \mathrm{~cm}$ long pre-separation column; current: $100 \mu \mathrm{A}$ ). 


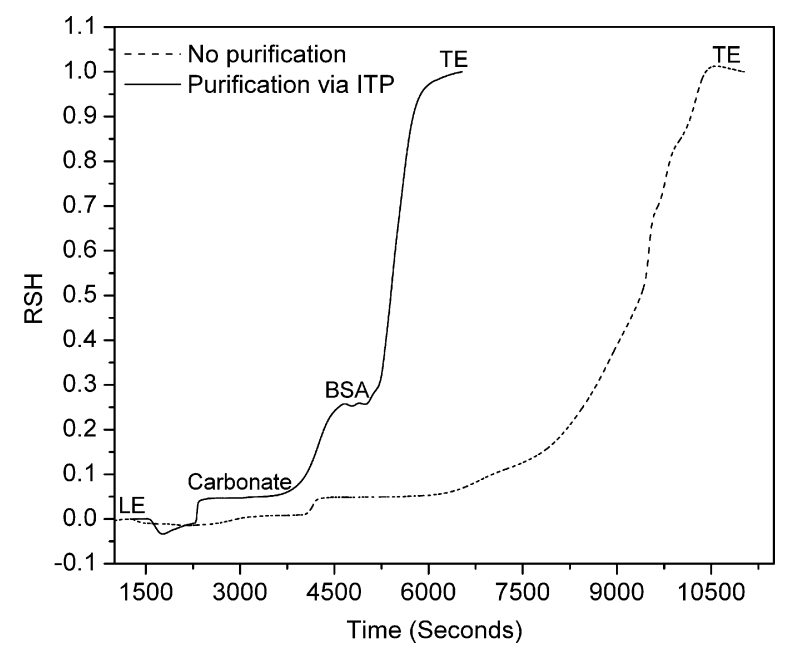

Fig. 3. A comparison of the conductivity traces of a crude sample and a sample prepared via ITP (column: analytical; current: $25 \mu \mathrm{A}$; sample: 10 times diluted juice containing $300 \mu \mathrm{g}$ of BSA; sample injection volume: $30 \mu \mathrm{l}$ ).

pre-separation column to separate the sample zone $\left(\mathrm{BB}^{\prime}\right)$ from the fast-moving, undesirable species in the juice (shown in Fig. 4). Fig. 5 compares the conductivity and UV absorbance signals of the sample prepared by using $16 \mathrm{~cm}$ and $9 \mathrm{~cm}$ long pre-separation columns respectively. It is clear that the sample prepared by using the $16 \mathrm{~cm}$ pre-separation column resulted in the formation of a distinct BSA zone.

Currently, the time required for removing unwanted components from sugarcane juice diluted by a factor of 10 and 2 via ITP is $\sim 30 \mathrm{~min}$ (Fig. 2) and $60 \mathrm{~min}$ (Fig. 4) respectively.

\subsection{Comparison of samples prepared via ITP, ultrafiltration and liming}

A comparison of UV traces of a raw sample and samples prepared by using liming, ultrafiltration and ITP is shown in Fig. 6.

In order to estimate the percentage of BSA recovered after sample preparation using the above mentioned sample preparation techniques, the areas under the relevant peaks in Fig. 6 were obtained. In particular, the percentage of BSA recovered after sample preparation using liming and ultrafiltration was estimated to be $19.9 \%$ and $10.8 \%$, while that using ITP was $56.6 \pm 5.2 \%$. In other words, it is clear that although BSA was present when the sam-

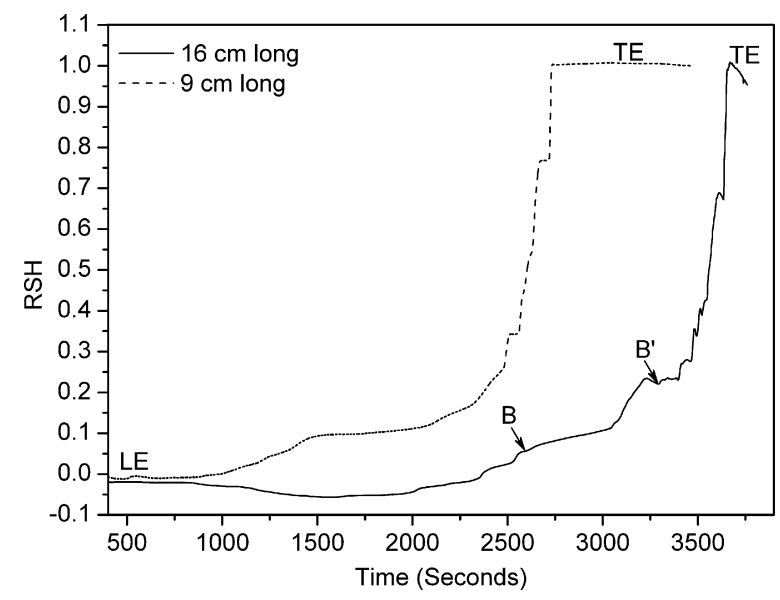

Fig. 4. Effect of length of pre-separation column on separation of sample zone from the interfering components in the juice (current: $100 \mu \mathrm{A}$; sample: 2 times diluted juice containing $300 \mu \mathrm{g}$ of BSA; sample injection volume: $30 \mu \mathrm{l}$ ).
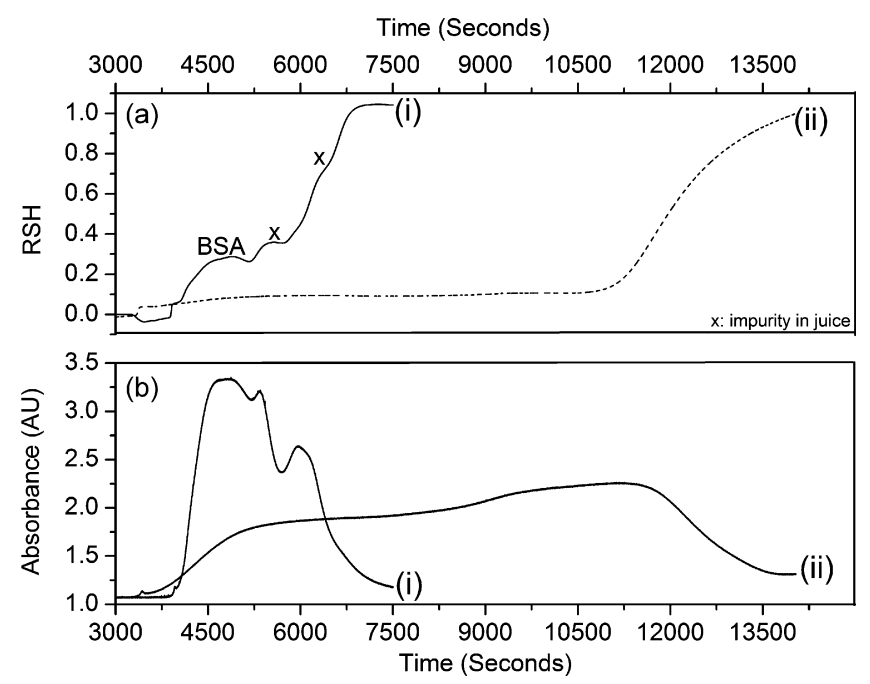

Fig. 5. A comparison of (a) conductivity and (b) UV-traces of the juice ( $2 \times$ dilution) containing $300 \mu \mathrm{g}$ of BSA prepared by using (i) $16 \mathrm{~cm}$ and (ii) $9 \mathrm{~cm}$ long pre-separation column measured at analytical column (sample injection volume: $30 \mu \mathrm{l})$.

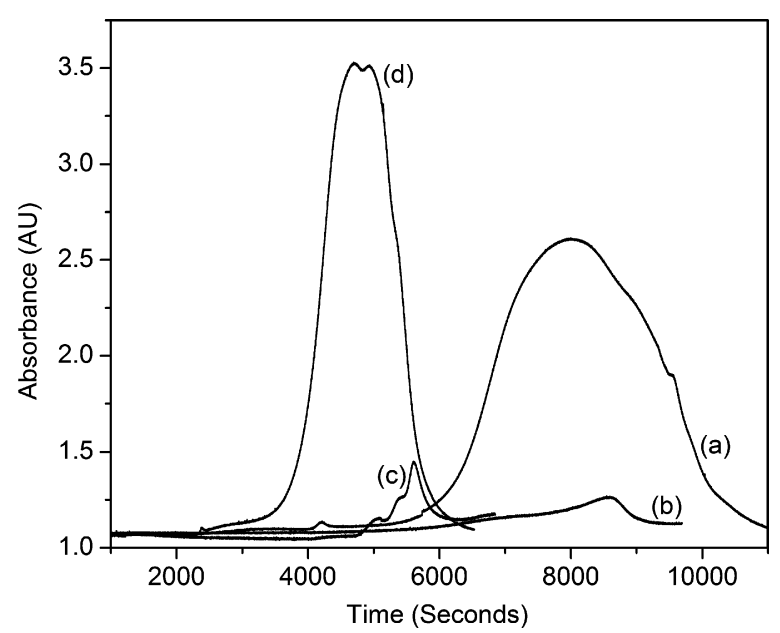

Fig. 6. A comparison of UV absorbance at $280 \mathrm{~nm}$ of juice $(10 \times$ dilution) with BSA undergoing (a) no sample preparation, (b) liming, (c) ultrafiltration and (d) ITP frontcutting method analyzed using isotachophoresis.

ple was either limed or filtered, this amount was much lower than the amount of BSA detected in the sample prepared using ITP. This could be due to the precipitation of BSA on adding calcium oxide or its degradation due to heating. Since a $10 \mathrm{kDa}$ MWCO was used to purify BSA (molecular weight $\sim 66 \mathrm{kDa}$ ), it is unlikely that the protein could not be retained by the membrane. Therefore, BSA was lost probably due its adsorption on the PES membrane surface. It should be noted that the amount of protein adsorption on membrane surfaces has to be characterized for each protein as this is dependent on the nature of the protein in question. This adds to the complexity of the membrane-based sample preparation. In other words, unlike ITP, liming and ultrafiltration are unsuitable for purification of BSA in the juice.

It should be noted that although BSA in sugarcane juice was used as a model sample solution in this study, the method developed is equally applicable to the purification of cellulases in the juice.

\section{Conclusions}

The cellulosic enzymes, i.e. BG, CBH and EG were sandwiched successfully between the leading and terminating electrolytes 
developed, thereby enabling their isotachophoretic migration. This work also demonstrated that ITP could be used successfully as a sample clean-up technique for BSA in sugarcane juice. Lower analysis time and reduction in sample loss due to adsorption are important factors in the favour of ITP. The other factors that make ITP an ideal technique for sample clean-up of BSA include its lower vulnerability to system blockages and higher amenability for automation. This is in addition to its ease of on-line integration with separation processes such as CZE. Hence, ITP is an ideal technique for sample clean-up of cellulases in sugarcane juice.

Finally, the method developed could be modified easily for the purification of these enzymes in culture mediums and fermentation broths which can then be analyzed by other techniques such as CZE.

\section{Acknowledgements}

This research was funded by Syngenta and the University of Manchester.

\section{References}

[1] G.C.G. Biswas, C. Ransom, M. Sticklen, Plant Sci. 171 (2006) 617

[2] M.V. Deshpande, K.E. Eriksson, L.G. Pettersson, Anal. Biochem. 138 (1984) 481

[3] K.R. Sharrock, J. Biochem. Biophys. Meth. 17 (1988) 81.

[4] J. Kolbe, C.P. Kubicek, App. Microbiol. Biotechnol. 34 (1990) 26

[5] M.Y. Khaled, H. McNair, L. Polite, R. Pauls, J. Microcolumn Sep. 7 (1995) 429.

[6] H. Jørgensen, T. Eriksson, J. Borjesson, F. Tjerneld, L. Olsson, Enzyme Microb. Technol. 32 (2003) 851.

[7] H. Jørgensen, J.P. Kutter, L. Olsson, Anal. Biochem. 317 (2003) 85.

[8] H. Jørgensen, A. Mørkeberg, K.B.R. Krogh, L. Olsson, Enzyme Microb. Technol $36(2005) 42$

[9] H. Jørgensen, L. Olsson, Enzyme Microb. Technol. 38 (2006) 381.

[10] J.R. Veraart, H. Lingeman, U.A.T. Brinkman, J. Chromatogr. A 856 (1999) 483.

[11] X. Wu, Trends Anal. Chem. 22 (2003) 48.
[12] T. Rubidge, Trans. Br. Mycol. Soc. 83 (1984) 522.

[13] P.G. Zaworski, G.S. Gill, Anal. Biochem. 173 (1988) 440.

[14] M.E. Himmel, J.O. Baker, R.P. Overend, Enzym. Conver. Biomass Fuels Product. 566 (1994) 130.

[15] T.M. Wood, Biochem. J. 109 (1968) 217.

[16] G. Halliwell, M. Riaz, Biochem. J. 116 (1970) 35.

[17] L.G. Fägerstam, L.G. Pettersson, FEBS Lett. 98 (1979) 363.

[18] H.J. Vogel, Microb. Genet. Bull. 13 (1956) 42

[19] J.C.P. Chen, C.C. Chou, Cane Sugar Handbook: A Manual for Cane Sugar Manufacturers and Their Chemists, 12th ed., John Wiley \& Sons, New York, 1993.

[20] M. Saska, N.G. Zapata, Int. Sugar J. 108 (2006) 203.

[21] G. Malmary, J. Albet, A. Putranto, H. Hanine, J. Molinier, J. Chem. Technol. Biotechnol. 75 (2000) 1169.

[22] G. Malmary, J. Albet, A. Putranto, H. Hanine, J. Molinier, J. Chem. Eng. Data 43 (1998) 849

[23] S.H. McMurray, G.H. Griffin, J. Chem. Technol. Biotechnol. 77 (2002) 1262.

[24] G. Eggleston, A. Monge, A. Pepperman, J. Agric. Food Chem. 50 (2002) 484.

[25] M. Balakrishnan, M. Dua, P.N. Khairnar, Sep. Sci. Technol. 36 (2001) 619.

[26] B. Farmani, M.H. Haddadekhodaparast, J. Hesari, S. Aharizad, J. Agric. Sci. Technol. 10 (2008) 351.

[27] N.K. Saha, M. Balakrishnan, M. Ulbricht, Desalination 189 (2006) 59.

[28] J.E. Prest, S.J. Baldock, P.R. Fielden, N.J. Goddard, B.J.T. Brown, Analyst 128 (2003) 1131.

[29] P. Mikuš, P. Kubačák, I. Valášková, E. Havránek, Talanta 70 (2006) 840

[30] M. Masár, M. Danková, E. Ölvecká, A. Stachurová, D. Kaniansky, B. Stanislawski, J. Chromatogr. A 1026 (2004) 31.

[31] R. Bodor, M. Žúborová, E. Ölvecká, V. Madajová, M. Masár, D. Kaniansky, B. Stanislawski, J. Sep. Sci. 24 (2001) 802.

[32] J.P. Landers, Handbook of Capillary and Microchip Electrophoresis and Associated Microtechniques, 3rd ed., CRC Press, 2008.

[33] F.M. Everaerts, J.L. Beckers, T.P.E.M. Verheggen, Isotachophoresis-Theory, Instrumentation and Applications, Elsevier, Amsterdam, 1976.

[34] L. Ludmila Kivánková, F. Foret, P. Gebauer, P. Boček, J. Chromatogr. 390 (1987) 3.

[35] W. Thormann, M.A. Firestone, J.E. Sloan, T.D. Long, R.A. Mosher, Electrophoresis 11 (1990) 298.

[36] S.G. Hjalmarsson, F.M. Everaerts, Crit. Rev. Anal. Chem. 11 (1981) 261.

[37] J.C. Reijenga, T.P.E.M. Verheggen, J.H.P.A. Martens, F.M. Everaerts, J. Chromatogr. A 744 (1996) 147.

[38] A.W.Jeremiasse, H.V.M. Hamelers, J.M. Kleijn, C.J.N. Buisman, Environ. Sci. Technol. 43 (2009) 6882. 